\title{
Epidemiological evaluation of apical periodontitis prevalence in an urban Brazilian population
}

\section{Teresa BERLINCK \\ Justine Monteiro Monnerat TINOCO \\ Fernanda Leal Fonseca de CARVALHO \\ Luciana Moura SASSONE \\ Eduardo Muniz Barretto TINOCO}

Universidade do Estado do Rio de Janeiro - UERJ, School of Dentistry, Departamento de Procedimentos Clínicos Integrados PROCLIN, Rio de Janeiro, RJ, Brazil.

Declaration of Interests: The authors certify that they have no commercial or associative interest that represents a conflict of interest in connection with the manuscript.

Corresponding Author:

Justine Monteiro Monnerat Tinoco

E-mail: justinemonnerat@yahoo.com.br

DOI: 10.1590/1807-3107BOR-2015.vol29.0051

Submitted: Sep 02, 2014

Accepted for publication: Jan 08, 2015

Last revision: Feb 11, 2015

\begin{abstract}
The present study aimed to assess the prevalence of apical periodontitis (AP) in an urban Brazilian population according to gender, age group and tooth type. Data were collected from clinical files containing the medical and dental histories and periapical radiographs of 1,126 patients treated at the School of Dentistry at Universidade do Estado do Rio de Janeiro between March 2000 and December 2010. A total of 15,724 periapical radiographs were evaluated. All the radiographs were evaluated by two independent, previously calibrated endodontists $(\mathrm{kappa}=0.88)$. Periapical areas on the radiographs were classified as $\mathrm{N}$ (normal) or AR (apical radiolucency). The frequency of $\mathrm{AP}$ and the $95 \%$ Confidence Interval $(95 \% \mathrm{CI})$ were calculated according to gender, age group and tooth type. Differences between groups were calculated using the Z-test at a significance level of $5 \%(\mathrm{p}<0.05)$. AP was present in $7.87 \%$ of the samples, with $16.70 \%$ occurring on previously endodontically treated teeth and $44.65 \%$ occurring on teeth referred for endodontic treatment (TR-RCT). The frequency of AP was higher among females (64\%) than among males (35\%). The central and lateral maxillary incisors were the most frequently affected teeth. The frequency of AP was higher among individuals between 30 and 49 years of age. In this population, AP was more prevalent among females and among individuals between 30 and 49 years of age, and the central and lateral maxillary incisors were the most frequently affected teeth.
\end{abstract}

Keywords: Periapical Periodontitis; Periodontitis; Radiography.

\section{Introduction}

Apical periodontitis (AP) is a complex multifactorial condition originating from an infected necrotic pulp or a failed endodontic treatment. AP often develops asymptomatically, and the prognosis is typically less favorable when it is detected late. Epidemiological studies on the prevalence of AP in different countries have revealed that AP is a widespread oral health problem that may jeopardize systemic health. ${ }^{1}$ AP affects a significant proportion of people in different populations, and several authors have reported frequencies in Kosovo (46.3\%), Turkey (67.9\%), Belgium (40\%), Denmark (52\%), Lithuania (39\%), Canada (44\% and 51\%), Germany (61\%), Scotland (51\%), Spain (64.5\%), and the United States (39\%). ${ }^{2,3,4}$

Results from cross-sectional studies have often associated AP with inadequate root-fillings, ${ }^{5}$ and the quality of the root filling has been 
extensively documented as the most important determinant of endodontic success. $5,6,7,8,9,10,11,12,13,14$ Certain authors have indicated that age, gender, social class, education, occupation and use of dental services are among the risk indicators that may be associated with the presence of apical periodontitis. ${ }^{10}$ Other descriptive epidemiological studies have suggested that the presence of an apical lesion is dependent on tooth type. ${ }^{11}$ The present study aimed to assess the prevalence of apical periodontitis in an urban Brazilian population according to gender, age group and tooth type.

\section{Methodology}

\section{Sample selection}

Data were collected from 1,126 clinical files containing medical and dental histories, dental exams and periapical radiographs of patients treated by undergraduate students at the Endodontics Clinic at the School of Dentistry at Universidade do Estado do Rio de Janeiro - UERJ between March 2000 and December 2010. The mean patient age was $37.1 \pm 16.4$ years, and the cohort contained 738 females $(65.55 \%)$ and 388 males (34.45\%). The study was approved by the Ethics Committee of the Hospital Universitário Pedro Ernesto (CEP-HUPE 2032-2008).

\section{Radiographic examination}

Radiographic evaluation was used to assess the number of endodontically treated teeth, endodontically treated teeth with apical radiolucency, teeth referred for endodontic treatment and teeth referred for endodontic treatment with apical radiolucency. A total of 15,724 periapical radiographs were evaluated. All teeth referred for endodontic treatment were treated at the Endodontics Clinic at the School of Dentistry at UERJ. The operatory radiographs of these teeth were taken using an Odontomax 70/7P X-ray unit (Odontomax, Astex, São Paulo, Brazil) with the paralleling technique and Kodak Intraoral E-speed film (Eastman Kodak, Rochester, USA). All the radiographs were evaluated by two independent, previously calibrated endodontists (kappa $=0.88)$. Radiographs with cuts, distortion, poor fit of the apical region, veiling or significant radiographic density alteration and images suggestive of endo- periodontal disease or root-end surgery were excluded $(n=664)$. The periapical status of each tooth was assessed using the Periapical Index (PAI) ${ }^{15}$ as follows:

- N (normal): the periodontal ligament space and the surrounding bone show no alteration (PAI scores 1 and 2);

- AR (apical radiolucency): the presence of apical radiolucency or widening of the periapical ligament space to greater than twice the normal width (PAI scores 3, 4 and 5).

The same environmental conditions were maintained at all times during the radiograph analysis. A film-observer distance of $20 \mathrm{~cm}$ was maintained throughout the analysis. The room was darkened, and a black mask was used around the radiograph to limit light emission from the illuminating viewing box.

\section{Statistical analysis}

The frequency of apical radiolucency and the 95\% Confidence Interval $(95 \% \mathrm{CI})$ were calculated according to gender, age group and tooth type. The Z-test for proportions was used to determine statistically significant differences between proportions. The significance level was set at $5 \%(\mathrm{p}<0.05)$. The prevalence of apical radiolucency was assigned as a dependent variable, and age group, gender and tooth type were included as independent variables. The Statistical Package for the Social Sciences (SPSS 8.0 for Windows, Tokyo, Japan) was used for data management.

\section{Results}

Through the radiographic analyses of 1,126 patients (total number of teeth $=25,292$ ), it was determined that 1,754 teeth had already received root canal treatment (RCT), of which 293 presented with apical radiolucency. In total, 3,807 teeth were candidates for referral for RCT, of which 1,700 presented with apical radiolucency. The prevalence of diabetes among the individuals in this sample was $18.48 \%$, and the prevalence of high blood pressure was $33.57 \%$. Three individuals had received a kidney transplant $(0.27 \%)$, and one individual had undergone a coronary heart valve replacement $(0.09 \%)$. The questionnaire used to assess the socioeconomic status of the population revealed that $70.33 \%$ of the individuals had only an elementary education degree and that $93.61 \%$ had a 
monthly income of 1 minimum wage. Table 1 shows the distribution of patients by age group.

Apical radiolucency was present in 1993/25292 (7.87\%) of the examined radiographs. Among previously endodontically treated teeth (PT-RCT), 293/1754 (16.70\%) showed apical radiolucency, and $1700 / 3807$ (44.65\%) of the teeth referred for endodontic treatment (TR-RCT) showed apical radiolucency. The distribution and prevalence of apical radiolucency by age group is shown in Table 2 .

The frequency of apical radiolucency was higher among females (62.41\% in TR-RCT; 66.21\% in PT-RCT) than among males $(37.59 \%$ in TR-RCT; $33.79 \%$ in PT-RCT), although women were overrepresented in this sample (Table 3 ).

The central and lateral maxillary incisors were the most frequently affected teeth $(10.87 \%$ and $7.70 \%$, respectively), followed by the mandibular second premolars and first molars $(3.60 \%$ and $3.44 \%$, respectively), among those teeth referred for endodontic

Table 1. Age distribution and percentage of the total sample ( $\mathrm{n}=1,126)$

\begin{tabular}{lcc}
\hline Age group & $N$ & $(\% ; \pm 95 C . I)$. \\
\hline $0-18$ & 125 & $11.1 \pm 1.83$ \\
$19-29$ & 215 & $19.09 \pm 2.3^{*}$ \\
$30-39$ & 213 & $18.92 \pm 2.29^{*}$ \\
$40-49$ & 265 & $23.53 \pm 2.48^{*}$ \\
$50-59$ & 178 & $1.60 \pm 0.73$ \\
$60+$ & 115 & $10.21 \pm 1.77$ \\
Total & 1,126 & 100.0 \\
\hline
\end{tabular}

*Statistically significant $(p<0.05)$ treatment. The central and lateral maxillary incisors were the most frequently affected teeth $(13.13 \%$ and $17.76 \%$, respectively), followed by the mandibular first molar and the second and first maxillary premolars $(21.77 \%, 13.77 \%$ and 12.57 , respectively), among the previously endodontically treated teeth (Table 4).

\section{Discussion}

This cross-sectional observational study aimed to describe the prevalence of periapical lesions in an urban Brazilian population using periapical radiographs and dental and medical histories. Although most studies are based on radiographic evaluation, certain authors have used other variables, such as clinical notes and interviews. ${ }^{9}$ Previously, periapical radiography was the only imaging method available to diagnose post-treatment apical periodontitis. ${ }^{16}$ Periapical radiographs were chosen to assess periapical radiolucency because they have a higher sensitivity in detecting periapical osteolytic lesions than panoramic radiographs, especially in the anterior region. ${ }^{17}$ Muhammed et al. ${ }^{18}$ found no statistically significant difference between panoramic radiographs and fullmouth surveys in detecting periapical lesions.

The population described in the present study represents a convenience sample from the School of Dentistry at UERJ and is not representative of the entire Brazilian population. Therefore, comparisons with other populations should be performed cautiously. Differences in health care system, age, and methodology are likely to contribute to discrepancies. ${ }^{19,20}$

Table 2. Frequency and distribution of apical radiolucency among teeth with previous endodontic treatment (PT-RCT) and among teeth referred for endodontic treatment (TR-RCT) by age group $(n=1,993)$

\begin{tabular}{lcccc} 
Age group & $\begin{array}{c}\text { Frequency in } \\
\text { PT-RCT }\end{array}$ & (\%; \pm 95 C.I.) & $\begin{array}{c}\text { Frequency in } \\
\text { TR-RCT }\end{array}$ & (\%; \pm 95 C.I.) \\
\hline $0-18$ & 21 & $7.16 \pm 2.95$ & 267 & $15.71 \pm 1.73$ \\
$19-29$ & 41 & $13.99 \pm 3.97$ & 283 & $16.65 \pm 1.77$ \\
$30-39$ & 79 & $26.97 \pm 5.08$ & 370 & $21.76 \pm 1.96$ \\
$40-49$ & 71 & $16.72 \pm 4.27$ & 373 & $21.94 \pm 1.97$ \\
$50-59$ & 49 & $10.92 \pm 3.57$ & 193 & $11.35 \pm 1.51$ \\
$60+$ & 32 & 0 & 54 & $9.41 \pm 1.39$ \\
Missing & 0 & 100.00 & 1,700 & $3.18 \pm 0.83$ \\
Total & 293 & & 100.00 \\
\hline
\end{tabular}


Table 3. Distribution of teeth with apical radiolucency among teeth with previous endodontic treatment (PT-RCT) and among teeth referred for endodontic treatment (TR-RCT) by gender $(n=1,993)$

\begin{tabular}{lcccc}
\hline Gender & Frequency in PT-RCT & $(\% \pm 95$ C.I.) & Frequency in TR-RCT & $(\% \pm 95$ C.I.) \\
Female & 194 & $66.21 \pm 5.42$ & 1,061 & $62.41 \pm 2.3$ \\
Male & 99 & $37.79 \pm 5.55$ & 639 & $37.59 \pm 2.3$ \\
\hline Total & 293 & 100.0 & 1,700 & 100.0 \\
\hline
\end{tabular}

Table 4. Prevalence of apical radiolucency (AP) according the tooth type among teeth with previous RCT (TP-RCT) and among teeth referred for RCT (TR-RCT) (percentage and 95\%CI).

\begin{tabular}{|c|c|c|c|c|c|c|}
\hline Tooth type & TP- RCT & $\mathrm{AP}$ & (\% of Total; $95 \%$ C.I.) & TR-RCT & AP & (\% of Total; $95 \%$ C.I.) \\
\hline \multicolumn{7}{|l|}{ Maxilla } \\
\hline Central incisors & 259 & 37 & $13.13+4.11$ & 811 & 414 & $10.87 \pm 0.99^{*}$ \\
\hline Lateral incisors & 214 & 41 & $17.76 \pm 5.12$ & 541 & 293 & $7.70 \pm 0.85^{*}$ \\
\hline Canines & 146 & 21 & $12.32 \pm 5.33$ & 299 & 124 & $3.26 \pm 0.56$ \\
\hline First premolars & 183 & 26 & $12.57 \pm 4.8$ & 330 & 126 & $3.31 \pm 0.57$ \\
\hline Second premolars & 167 & 26 & $13.77 \pm 5.23$ & 367 & 121 & $3.18 \pm 0.56$ \\
\hline First molars & 139 & 15 & $8.63 \pm 4.67$ & 88 & 27 & $0.71 \pm 0.27$ \\
\hline Second molars & 50 & 7 & $6 \pm 6.58$ & 21 & 2 & $0.05 \pm 0.07$ \\
\hline Third molars & 5 & 0 & $0 \pm 0$ & 0 & 0 & 0.0 \\
\hline Subtotal & 1,163 & 173 & $4.38 \pm 4.18$ & 2,457 & 1,107 & $29.08 \pm 1.44^{* *}$ \\
\hline \multicolumn{7}{|l|}{ Mandible } \\
\hline Central incisors & 22 & 14 & $63.59 \pm 20.89$ & 95 & 70 & $1.84 \pm 0.43$ \\
\hline Lateral incisors & 26 & 8 & $19.23 \pm 15.15$ & 81 & 52 & $1.37 \pm 0.37$ \\
\hline Canines & 47 & 9 & $12.76 \pm 9.54$ & 119 & 55 & $1.44 \pm 0.38$ \\
\hline First premolars & 112 & 20 & $15.17 \pm 6.64$ & 195 & 85 & $2.23 \pm 0.47$ \\
\hline Second premolars & 117 & 16 & $11.11 \pm 5.69$ & 342 & 137 & $3.60 \pm 0.59$ \\
\hline First molars & 147 & 34 & $21.77 \pm 6.67$ & 324 & 131 & $3.44 \pm 0.58$ \\
\hline Second molars & 107 & 19 & $14.95 \pm 6.76$ & 149 & 54 & $1.42 \pm 0.38$ \\
\hline Third molars & 13 & 0 & $0 \pm 0$ & 14 & 3 & $0.08 \pm 0.09$ \\
\hline Subtotal & 591 & 120 & $16.92 \pm 3.02$ & 1,319 & 587 & $15.42 \pm 1.15^{* *}$ \\
\hline Missing values & 0 & 0 & 0 & 18 & 6 & $0.16 \pm 0.13$ \\
\hline Unclassified teeth & 0 & 0 & 0 & 13 & 0 & 0.0 \\
\hline Total & 1,754 & 293 & $14.31 \pm 1.64$ & 3,807 & 1,700 & $44.65 \pm 1.58$ \\
\hline
\end{tabular}

*Not statistically significant ( $p>0.05)$.

**Statistically significant $(p<0.05)$.

The number of individuals aged 40-49 years was significantly higher than that for the other age groups, with the exception of the 30-39 age group, suggesting that individuals of this age more frequently seek dental service. The mean age of the population described in the present study (37.1 \pm 16.4 years) is similar to that described by Eriksen et al. ${ }^{7}$ but is lower than those reported by Tsuneishi et al..$^{13}$ (50.8 years of age) and Georgopoulou et al..$^{20}$ (48.0 years of age).
Certain authors have shown an increase in both the prevalence of root-filled teeth and the presence of apical periodontitis with increasing patient age. ${ }^{7,13,19,20,21}$ The results presented herein revealed that the prevalence of apical periodontitis among teeth with previous endodontic treatment or teeth referred for endodontic treatment was highest in the 40-49 age group, followed by the 30-39 age group. Both the 50-59 and the 60+ age groups contained fewer patients with AP. Other studies 
have reported the same skewed age distribution., ${ }^{4,22}$ One possible explanation is that younger individuals seek dental treatment at dental schools more often than older individuals due to the lower treatment cost at dental schools. Additionally, one cannot eliminate the possibility that older persons may undergo more tooth extractions rather than root canal treatments. Nevertheless, there was no statistically significant difference in the prevalence of AP between the age groups $(p=0.068)$.

The sample in our study contained more females (63.98\%) than males (36.02\%). Previous surveys that have reported similar results explained this gender discrepancy as occurring because women have a greater interest in receiving dental care. ${ }^{19,20}$ The present study showed a significant difference in AP between men $(37.59 \%)$ and women $(62.41 \%)(p<0.05)$, which may be explained by the smaller number of males in this sample.

Most studies have shown that molars and premolars are the most common root-filled teeth ${ }^{13,20}$ with associated $\mathrm{AP}^{8,11,21}$ The present results indicated that the central and lateral maxillary incisors were the most frequently affected teeth, followed by the premolars and the mandibular first molars. This difference could be explained by the socioeconomic status of our sample population; this population probably chose tooth extraction rather than root canal treatment followed by costly prosthetic treatment. In addition, central and lateral maxillary incisors are the teeth most frequently affected by trauma, which is often associated with AP lesions.

Indeed, socioeconomic variables have been frequently associated with AP. In our sample, $70.33 \%$ of the patients had only an elementary education degree, and $93.61 \%$ had a monthly income of 1 minimum wage. These variables provide a broad overview of the social class, living conditions and general health of the patients, although these variables may only indirectly affect disease occurrence. Other studies have indicated that regular dental care and caries experiences are strong disease determinants. ${ }^{21}$

Our study sample consisted of teeth that had been endodontically treated or had been referred for endodontic treatment. In the present study, $16.7 \%$ of the cases that had previous endodontic treatment also presented with apical periodontitis. This prevalence was similar to those previously reported. ${ }^{13,23}$ In cases that were referred for endodontic treatment, $44.65 \%$ of the patients presented with apical periodontitis; this prevalence is similar to that reported in other countries (16\%-65\%). $4,6,21,22,24,25$ Certain studies have described a higher prevalence of apical periodontitis (60\%-67.5\%). ${ }^{19,20}$ According to Khabbaz et al., ${ }^{26}$ poorer dental health and inappropriate techniques may contribute to this higher prevalence.

Kirkevang and Wenze $\mathrm{l}^{10}$ have classified risk indicators for apical periodontitis, and they concluded that the most important risk indicator for apical periodontitis was radiographic evidence of root fillings. This finding is supported by several epidemiological studies. ${ }^{4,6,7,11,19,20,22,24,26,27,28,29,30,31} \mathrm{Ng}$ et al. ${ }^{32}$ demonstrated the need to improve the technical quality of root fillings performed by undergraduate students, especially in molars. The technical quality of the root canal treatment and coronal restoration has a significant impact on the periapical health of root-filled teeth.

Apical periodontitis (AP) is a common sequela of pulp infection, ${ }^{33}$ and the local inflammatory process aims to confine and limit the spread of infectious elements. ${ }^{34}$ However, in AP, pulpal and periapical infection can potentially spread throughout the body, this being the most serious endodontic pathological condition from a general health view. ${ }^{35}$ The association between inflammation of endodontic origin and systemic health has not been adequately reported in the scientific literature. ${ }^{36,37,38}$ The available scientific evidence is limited, but it is consistent in suggesting that AP may contribute to a systemic immune response that is not confined to the localized lesion, potentially leading to increased systemic inflammation. ${ }^{39}$ Chronic apical periodontitis has been independently associated with coronary heart disease (CHD) ${ }^{38}$ and surgical endodontic treatment has been demonstrated to reduce systemic inflammation. ${ }^{40}$ These studies highlight the relevance of AP and the need for more studies on the epidemiology, etiology and risk factors of this important oral condition.

\section{Conclusion}

In this sample population, the frequency of $\mathrm{AP}$ was higher among individuals in the 30-49 age group; females were more often affected than males, and the central and lateral maxillary incisors were the most frequently affected teeth. 


\section{References}

1. Segura-Egea J, Castellanos-Cosano L, Machuca G, Lopez-Lopez J, Martin-Gonzalez J, Velasco-Ortega E, et al. Diabetes mellitus, periapical inflammation and endodontic treatment outcome. Med Oral Patol Oral Cir Bucal. 2012 Mar 1;17(2):e356-61.

2. Eriksen HM, Berset GP, Hansen BF, Bjertness E. Changes in endodontic status 1973-1993 among 35-year-olds in Oslo, Norway. Int Endod J. 1995 May;28(3):129-32.

3. Weiger R, Hitzler S, Hermle G, Löst C. Periapical status, quality of root canal fillings and estimated endodontic treatment needs in an urban German population. Endod Dent Traumatol. 1997 Apr;13(2):69-74.

4. De Moor RJG, Hommez GMG, De Boever JG, Delme KIM, Martens GEI. Periapical health related to the quality of root canal treatment in a Belgian population. Int Endod J. 2000 Mar;33(2):113-20.

5. Kirkevang LL, Vaeth M, Hörsted-Bindslev P, Wenzel A. Longitudinal study of periapical and endodontic status in a Danish population. Int Endod J. 2006 Feb;39(2):100-7.

6. Marques MD, Moreira B, Eriksen HM. Prevalence of apical periodontitis and results of endodontic treatment in an adult, Portuguese population. Int Endod J. 1998 May;31(3):161-5.

7. Eriksen HM, Kirkevang LL, Petersson K. Endodontic epidemiology and treatment outcome: general considerations. Endod Topics. 2002 July;2(1):1-9.

8. Lupi-Pegurier L, Bertrand MF, Muller-Bolla M, Rocca JP, Bolla M. Periapical status, prevalence and quality of endodontic treatment in an adult French population. Int Endod J. 2002 Aug;35(8):690-7.

9. Dugas NN, Lawrence HP, Teplitsky PE, Pharoah MJ, Friedman S. Periapical health and treatment quality assessment of root filled teeth in two Canadian populations. Int Endod J. 2003 Mar;36(3):181-92.

10. Kirkevang LL, Wenzel A. Risk indicators for apical periodontitis. Community Dent Oral Epidemiol. 2003 Feb;31(1):59-67.

11. Loftus JJ, Keating AP, McCartan BE. Periapical status and quality of endodontic treatment in an adult Irish population. Int Endod J. 2005 Feb;38(2):81-6.

12. Siqueira Junior JF, Rôças IN, Alves FRF, Campos LC. Periradicular status related to the quality of coronal restorations and root canal fillings in Brazilian population. Oral Surg Oral Med Oral Pathol Oral Radiol Endod. 2005 Sep;100(3):369-74.

13. Tsuneishi M, Yamamoto T, Yamanaka R, Tamaki N, Sakamoto $\mathrm{T}$, Tsuji K, et al. Radiographic evaluation of periapical status and prevalence of endodontic treatment in an adult Japanese population. Oral Surg Oral Med Oral Pathol Oral Radiol. 2005 Nov;100(5):631-5.

14. Imura N, Pinheiro ET, Gomes B, Zaia AA, Ferraz C, SouzaFilho F. The outcome of endodontic treatment: a retrospective study of 2000 cases performed by a specialist. J Endod. 2007 Nov;33(11):1278-82.
15. Ørstavik D, Kerekes K, Eriksen HM. The Periapical index: a scoring system for radiographic assessment of apical periodontitis. Endod Dent Traumatol. 1986 Feb;2(1): 20-34.

16. Wu MK, Shemesh H, Wesselink PR. Limitations of previously published systematic reviews evaluating the outcome of endodontic treatment. Int Endod J. 2009 Aug;42(8):656-66.

17. Molander B, Ahlqwist M, Gröndahl HG. Panoramic and restrictive intraoral radiography in comprehensive oral radiographic diagnosis. Eur J Oral Sci. 1995 Aug;103(4):191-8.

18. Muhammed AH, Manson-Hing LR, Ala B. A comparison of panoramic and intraoral radiographic surveys in evaluating a dental clinic population. Oral Surg Oral Med Oral Pathol. 1982 Jul;54(1):108-17.

19. Jiménez-Pinzón A, Segura-Egea JJ, Poyato-Ferrera M, Velasco-Ortega E, Ríos-Santos JV. Prevalence of apical periodontitis and frequency of root-filled teeth in aldult Spanish population. Int Endod J. 2004 Mar;37(3):167-73.

20. Georgopoulou MK, Spanaki-Voreadi AP, Pantazis N, Kontakiotis EG. Frequency and distribution of root filled teeth and apical periodontitis in a Greek population. Int Endod J. 2005 Feb;38(2):105-11.

21. Kirkevang LL, Horsted-Bindslev P, Orstavik D, Wenzel A. Frequency and distribution of endodontically treated teeth and apical periodontitis in an urban Danish population. Int Endod J. 2001 Apr;34(3):198-205.

22. De Cleen MJ, Schuurs AH, Wesselink PR, Wu MK. Periapical status and prevalence of endodontic treatment in an adult Dutch population. Int Endod J. 1993 Mar;26(2):112-9.

23. Eckerbom M, Flygare L, Magnusson T. A 20-year follow-up study of endodontic variables and apical status in a Swedish population. Int Endod J. 2007 Dec;40(12):940-8.

24. Buckley M, Spangberg LS. The prevalence and technical quality of endodontic treatment in an American subpopulation. Oral Surg Oral Med Oral Pathol Oral Radiol Endod. 1995 Jan;79(1):92-100.

25. Tronstad L, Asbjørnsen K, Døving L, Pedersen I, Eriksen HM. Influence of coronal restorations on the periapical health of endodontically treated teeth. Endod Dent Traumatol. 2000 Oct;16(5):218-21.

26. Khabbaz MG, Protogerou E, Douka E. Radiographic quality of root fillings performed by undergraduate students. Int Endod J. 2010 Jun;43(6):499-508.

27. Eriksen HM, Bjertness E. Prevalence of apical periodontitis and results of endodontic treatment in middle-aged adults in Norway. Endod Dent Traumatol. 1991 Feb;7(1):1-4.

28. Figdor D. Apical periodontitis: a very prevalent problem. Oral Surg Oral Med Oral Pathol Oral Radiol Endod. 2002 Dec;94(6):651-2.

29. Santos SMC, Soares JA, Costa GM, Brito-Júnior M, Moreira AN, Magalhães CS. Radiographic parameters of quality of root canal fillings and periapical status: a retrospective cohort study. J Endod. 2010 Dec;36(12):1932-7. 
30. Boltacz-Rzepkowska E, Pawlicka H. Radiographic features and outcome of root canal treatment carried out in the Lodz region of Poland. Int Endod J. 2003 Jan;36(1):27-32.

31. Barrieshi-Nusair KM, Al-Omari MA, Al-Hiyasat AS. Radiographic technical quality of root canal treatment performed by dental students at the Dental Teaching Center in Jordan. J Dent. 2004 May;32(4):301-7.

32. Ng Y-L, Mann V, Gulabivala K. Outcome of secondary root canal treatment: a systematic review of the literature. Int Endod J. 2008 Dec;41(12):1026-46.

33. Caplan DJ. Epidemiologic issues in studies of association between apical periodontitis and systemic health. Endod Topics. 2004 Jul;8(1):15-35.

34. Segura-Egea JJ, Castellanos-Cosano L, Machuca G, LópezLópez J, Martín-González J, Velasco-Ortega E, et al. Diabetes mellitus, periapical inflammation and endodontic treatment outcome. Med Oral Patol Oral Cir Bucal. 2012 Mar 1;17(2):e356-61.
35. Márton IJ, Bergenholtz G. The periapical inflammatory process - systemic and local manifestations: introduction. Endod Topics. 2004 Jul;8(1):1-2.

36. Buttke TM, Shipper G, Delano EO, Trope M. C-reactive protein and serum amyloid $\mathrm{A}$ in a canine model of chronic apical periodontitis. J Endod. 2005 Oct;31(10):728-32.

37. Joshipura KJ, Pitiphat W, Hung HC, Willett WC, Colditz GA, Douglass CW. Pulpal inflammation and incidence of coronary heart disease. J Endod. 2006 Feb;32(2):99-103.

38. Costa TH, Figueiredo Neto JA, Oliveira AE, Maia MFL, Almeida AL. Association between chronic apical periodontitis and coronary artery disease. J Endod. 2014 Feb;40(2):164-7.

39. Gomes MS, Blattner TC, Sant'Ana Filho M, Grecca FS, Hugo FN, Fouad AF, et al. Can apical periodontitis modify systemic levels of inflammatory markers? A systematic review and meta-analysis. J Endod. 2013 Oct;39(10):1205-17.

40. Marton IJ, Kiss C. Influence of surgical treatment of periapical lesions on serum and blood levels of inflammatory mediators. Int Endod J. 1992 Sep;25(5):229-33. 